\title{
Pembentukan Cabang Lateral Jarak Pagar (Jatropha curcas) Setelah Perlakuan Girdling
}

\author{
Sri Darmanti * \\ Laboratorium Biologi Struktur dan Fungsi Tumbuhan, Jurusan Biologi FMIPA Undip
}

\begin{abstract}
Abstrak
Jarak Pagar (Jatropha curcas) merupakan tanaman yang pontensial sebagai sumber BBM yang terbarukan. Oleh karena itu peningkatan produksi biji jarak diperlukan untuk mendukung produksi BBM ini. Karena buah Jarak Pagar hanya terbentuk pada ujung batang dan ketiak daun yang dekat dengan ujung batang, maka jumlah cabang yang banyak diperlukan untuk mendapatkan produksi biji jarak yang tinggi. Pembentukan cabang lateral dipengaruhi oleh keseimbangan fitohormon antara lain sitokinin dan auksin. Girdling merupakan teknik untuk mengatur keseimbangan kedua fitohormon tersebut. Pada penelitian ini, perlakuan girdling dilakukan terhadap tanaman jarak dari stek yang berumur 5 bulan. Setiap perlakuan dengan 5 ulangan. Pengamatan dilakukan setiap satu bulan dan diakhiri setelah 6 bulan. Dari hasil pengamatan diperoleh hasil bahwa perlakuan girdling berpengaruh memacu pembentukan cabang lateral sedangkan tanaman control tidak membentuk cabang lateral sampai akhir perlakuan.
\end{abstract}

Kata Kunci : girdling, cabang lateral, Jatropa curcas.

\section{PENDAHULUAN}

Terjadinya krisis energi, khususnya bahan bakar minyak (BBM) telah menyadarkan semua fihak tentang perlunya mencari bahan bakar alternative khususnya yang terbarukan. Salah satu yang dipandang potensial dari kelompok tanaman adalah jarak pagar (Jatropha curcas). Jarak pagar termasuk familia Euphorbiaceae, tanaman perdu dengan percabangan yang tidak teratur, cabang terbentuk di ketiak daun, mempunyai daun tunggal, bunga majemuk berbentuk malai, berkelamin tunggal dan berumah satu, bunga jantan dan betina tersususun dalam rangkaian yang tumbuh pada ujung batang atau ketiak daun, buah berupa buah kotak terbagi dalam tiga ruang (Prihandana dan Hendroko, 2006).

Jarak pagar dianggap sebagai sumber bahan bakar alternative terbarukan yang potensial, karena tanaman ini mempunyai banyak keunggulan dibandingkan sumber nabati lainnya, yaitu antara lain adalah : relative mudah dibudidayakan, tumbuh dengan baik pada kondisi kering dengan curah hujan kurang dari $500 \mathrm{~mm}$ per tahun, maupun pada lahan dengan kesuburan rendah yaitu lahan marginal atau lahan kritis sehingga dapat menunjang usaha konversi lahan. Bersifat non edible, sehingga terhindar dari kemungkinan kompetisi pemanfaatan untuk bahan pangan manusia atau pakan ternak. Proses pengolahan minyak jarak kasar atau untuk kebutuhan rumah tangga pengganti minyak tanah dan untuk pembakaran tungku atau boiler sangat sederhana sehingga mudah dilakukan hingga ke pelosok oleh petani. Pengolahan untuk bahan bakar motor pengganti minyak solar juga tidak memerlukan teknologi tinggi sehingga biaya investasinya relative lebih murah (Mahmud, 2006).

Untuk mendukung produksi bahan bakar terbarukan ini maka berbagai usaha perlu dilakukan. Selain teknologi pengolahan biji jarak pagar menjadi BBM, yang tidak kalah pentingnya adalah pengembangan budidaya jarak pagar untuk menyediakan bahan baku sebanyak-banyaknya, baik dalam hal perbanyakan tanaman, pembibitan, penanaman, pemupukan, pola tanam, dan pengendalian hama penyakit. Karena bunga jarak pagar hanya terbentuk di ujung batang dan ketiak daun yang dekat dengan ujung batang, maka produksi buah sangat ditentukan oleh jumlah cabang yang terbentuk pada setiap tanaman.

Pada beberapa tanaman, pertumbuhan ujung batang sering mendominasi pertumbuhan bagian lain sehingga pembentukan cabang lateral dihambat. Fenomena ini disebut sebagai dominansi apical. Pada sebagian besar tanaman, apabila pertumbuhan batang sudah cukup, secara alami cabang lateral akan tumbuh pada nodus bagian bawah yang cukup jauh dari ujung batang, hal ini disebabkan karena semakin jauh dari ujung batang 
pengaruh dominansi apical semakin berkurang. Berdasarkan kekuatan dominansi apical, tanaman dibedakan menjadi dua yaitu dominansi apical yang kuat seperti pada tanaman Kalanchoe dan Bryophyllum dan dominansi apical yang lemah seprti pada $S$. tubeorsum dan Solanum lycopersicum. Dominansi apical dan pembentukan cabang lateral ini dipengaruhi oleh keseimbangan konsentrasi hormone (Khrishnamoorthy, 1981; Taiz and Zeiger, 1998 dan Hopkins, 1995).

Girdling adalah penghilangan floem secara melingkar pada batang (Hopkins, 1995). Untuk mencegah agar tidak terbentuk floem pada girdl, pada bagian floem yang dihilangkan tersebut dapat dililitkan kawat atau tali. Prinsip dari perlakuan tersebut adalah untuk mengatur keseimbangan hormone pada ketiak daun di bawah ujung batang (Taiz and Zeiger, 1998 dan Hopkins, 1995). Sintesis auksin terjadi pada bagian tanaman yang sedang mengalami pertumbuhan atau pada bagian meristematis, terutama pada ujung batang atau pada daun muda yang sedang tumbuh membentang. Bebarapa teori menerangkan tentang fenomena dominansi apical ini, "Direct Theory of Auksin" oleh Thimann menerangkan bahwa auksin yang disintesisi pada ujung batang akan ditransport secara basipetal ke bagian batang yang lebih bawah. Hal ini menyebabakan terakumulasinya auksin pada ketiak daun dibawahnya yang berakibat inisiasi pembentukan tunas lateral pada ketiak daun terhambat atau terjadi dormansi tunas lateral. Karena inisiasi pembentukan tunas lateral mensyaratkan konsentrasi auksin yang lebih rendah dibandingkan konsentrasi auksin optimal untuk pertumbuhan memanjang batang. Sedang "Nutritive Diversion Theory " menerangkan bahwa arah distribusi nutrisi dan metabolit dikontrol oleh auksin. Sintesis auksin terjadi di apical batang dan daun-daun muda yang sedang tumbuh. Auksin tersebut kemudian ditransport secara basipetal ke bagian bawah. Meskipun demikian, konsentrasi auksin pada bagian apical tetap lebih tinggi dibandingkan dengan bagian di bawah apical batang. Nutrisi atau metabolit lebih banyak ditransport ke bagian tanaman yang mempunyai konsentrasi auksin tinggi, sehingga nutrisi dan metabolit akan lebih banyak ditransport ke apical batang sehingga pertumbuhan apical batang akan menekan pertumbuhan cabang lateral. (Khrishnamoorthy, 1981).

Pada perlakuan girdling, sintesis auksin di ujung batang tetap berlangsung tetapi transportnya melalui floem dihambat sehingga konsentrasi auksin di nodus atau ketiak daun yang terdapat di bawah girdl semakin rendah. Dengan turunnya auksin di ketiak daun akan memacu pembentukan hormone sitokinin (Taiz dan Zeiger, 1998). Menurut Sato dan Mori (2001), pemacuan sintesisi sitokinin oleh turunnya konsentrasi auksin ini tidak secara langsung, tetapi melalui pengaktifan enzim isopentenil transferase yang merupakan katalisator pada pembentukan sitokinin.

Dari latar belakang diatas, maka perlu untuk di kaji seberapa efektif perlakuan girdling dapat memacu pembentukan tunas lateral, yang diharapkan dengan bertambahnya jumlah cabang lateral pada akhirnya dapat meningkatkan produksi biji jarak pagar.

\section{BAHAN DAN METODE}

a. Persiapan

Bahan untuk perlakuan girdling adalah tanaman jarak pagar yang berasal dari stek batang berumur 5 bulan. Perlakuan dan control masing - masing dengan 5 ulangan.

\section{b. Perlakuan}

Pada perlakuan ini bahan tanaman jarak pagar hasil stek sudah mempunyai 2-3 cabang. Pada tiap tanaman dipilih satu cabang yang paling panjang untuk diberi perlakuan girdling. Girdling dibuat pada pertengahan panjang batang. Girld dibuat dengan membuang bagian floem melingkar batang setebal $0,5 \mathrm{~cm}$. Pada bagian girdl tersebut kemudian dililitkan tali (kabel listrik yang dilapisi karet), agar tidak terbentuk lapisan floem yang baru.

c. Pemeliharaan.

Pada semua tanaman perlakuan dan tanaman kontrol dilakukan penyiraman dan pemupukan dengan volume dan frekwensi penyiraman yang sama.

\section{d. Pengamatan.}

Pengamatan dilakukan setiap bulan sampai 6 bulan perlakuan, dicatat waktu pembentukan cabang lateral dan jumlah cabang lateral yang terbentuk. 


\section{HASIL DAN PEMBAHASAN}

Perlakuan girdling dilakukan terhadap tanaman Jarak pagar yang berasal dari stek batang yang telah berumur 5 bulan. Pada semua tanaman ini telah tumbuh 2 sampai 3 batang cabang. Tetapi tiap tanaman hanya dipilih satu cabang untuk diberi perlakuan girdling. Hal ini dimaksudkan untuk membandingkan pembentukan cabang lateral pada batang yang diberi perlakuan girdling dan tidak diberi perlakuan girdling pada satu tanaman yang sama.

Dari hasil pengamatan diketahui bahwa sampai akhir perlakuan, yaitu pada saat tanaman berumur 11 bulan pada semua cabang yang diberi perlakuan girdling terbentuk 2 cabang lateral pada bulan ke 2 setelah perlakuan yaitu pada nodus pertama dan kedua dibawah girdl dan sampai akhir perlakuan tidak terdapat penambahan cabang baru. Sedang pada semua batang tanaman control tidak terbentuk cabang lateral. Data dalam bentuk tabel dapat dilihat sebagai berikut :

Tabel 1. Jumlah cabang lateral dan waktu terbentuknya cabang lateral Jarak pagar (Jatropha curcas) setelah perlakuan girdling.

\begin{tabular}{lcc}
\hline & GIRDLING & KONTROL \\
\hline Jumlah cabang lateral & 2 & 0 \\
$\begin{array}{l}\text { Waktu terbentuknya } \\
\text { cabang lateral (Bln ke) }\end{array}$ & 2 & - \\
\hline
\end{tabular}

Pertumbuhan sel, jaringan maupun organ yang menyusun tubuh tumbuhan saling tergantung satu sama lain, dimana pemacuan pertumbuhan pada satu bagian mungkin akan menekan pertumbuhan bagian lain dari tumbuhan tersebut. Hal yang demikian itu disebut sebagai fenomena korelasi pertumbuhan, yang tidak hanya melibatkan zat hara tetapi juga fitohormon sebagai factor pengatur. Salah satu contoh korelasi pertumbuhan adalah dominansi apical, yaitu pengaturan pertumbuhan dominansi ujung tanaman yang menekan pertumbuhan daerah meristematik yang lain seperti tunas lateral (Wareing dan Phillips, 1981; Wilkins, 1989).

Secara alami pada umur tertentu atau pada ukuran tertentu, sebagian besar tanaman termasuk jarak pagar mampu membentuk cabang lateral. Hal ini disebabkan karena semakin jauh dari pucuk maka pengaruh dominansi apical akan semakin lemah hingga pada jarak tertentu dari ujung pengaruh dominansi apikal akan hilang dan kemudian pada tempat tersebut akan tumbuh cabang lateral. Pada penelitian ini sampai akhir perlakuan yaitu umur tanaman 11 bulan, pada tanaman control tidak menunjukkan pertumbuhan tunas lateral. Hal ini disebabkan karena pada umur tersebut pertumbuhan cabang lateral tertekan oleh pertumbuhan apical batang. Yang berarti bahwa dominansi apical masih berpengaruh kuat sepanjang batang atau cabang yang tidak diberi perlakukan girdling dan tanaman control.

Jaringan tumbuhan mengandung lebih dari satu macam hormone, hormone- hormon tersebut mungkin mempunyai efek yang sama atau tidak sama. Efek hormone tersebut bisa komulatif, sinergis atau antagonis. Keseimbangan di antara hormone tersebut penting untuk perkembangan tumbuhan yang normal. Pengaruh fitohormon yang sama dapat berbeda pada tanaman yang berbeda, pada musim yang berbeda, juga tergantung pada interaksi dengan metabolit yang lain dan sensitifitas jaringan terhadap fitohormon yang bersangkutan (Lyndon 1990 ; Devies, 1995). Peristiwa dominansi apical berkaitan dengan peranan berbagai jenis hormone dan interaksi antara hormone - hormone tersebut. Heddy (1989) berpendapat bahwa auksin, sitokinin, etilen dan ABA perperan dalam peristiwa dominansi apical ini. Khrishnamoorthy, 1981; Taiz dan Zeiger, 1998 dan Hopkins, 1995 menerangkan fenomena ini dengan teori keseimbangan hormone auksin dengan sitokinin (direct theory of auksin). Auksin disintesis pada bagian tanaman yang sedang aktif mengalami pertumbuhan antara lain di bagian apical batang. Secara basipetal, auksin tersebut ditransport ke bagian bawah secara terus menerus sehingga konsentrasi auksin pada bagian nodus (ketiak daun) cukup tinggi. Konsentrasi auksin yang cukup tinggi ini akan menghambat aktifitas enzim isopentenil transferase yang merupakan katalisator pembentukan sitokinin, sehingga sintesis sitokinin dihambat. Keseimbangan konsentrasi sitokinin yang rendah dan auksin yang tinggi ini akan menghambat diferansiasi sel pada nodus untuk membentuk primordia cabang. Selain itu, konsentrasi IAA yang tinggi dan terhambatnya aktifitas enzim isopentenil transferase di nodus secara tidak langsung akan berakibat memacu 
sintesis ABA yang akan menghambat pertumbuhan cabang lateral.

Pada batang yang diberi perlakuan, dua cabang lateral tumbuh dibawah girdl setelah 2 bulan perlakuan. Hal ini desebabkan karena pada saat itu pengaruh dominansi apical pada dua nodus dibawah perlakuan girdl telah hilang. Girdl menyebabkan terhambatnya transport auksin dari meristem apical ke bawah. Hal ini sesuai dengan pendapat Hoad (1995) bahwa transport auksin melalui floem, sedang menurut Salisbury dan Ross (1991) transport auksin melalui sel-sel parenkim yang mengelilingi floem. Menurut direct theory of auksin, hal ini kemudian akan menyebabkan konsentrasi auksin di bagian nodus yang berada di bawah apical batang makin lama makin berkurang. Rendahnya konsentrasi auksin pada nodus ini akan memacu aktfiitas enzim isopentenil transferase yang merupakan katalisator pada sintesis sitokinin, sehingga sintesis sitokinin dipacu (Sato dan Mori, 2001). Keseimbangan konsentrasi sitokinin tinggi dan auksin rendah ini akan memacu terjadinya pembelahan dan diferensiasi sel pada nodus untuk membentuk primordia cabang lateral. Selanjutnya seperti yang dikatakan Khrishnamoorthy ( 1981), bahwa pada peristiwa pematahan dominansi apical seperti pada perlakuan girdling ini sitokinin berpengaruh memacu diferensiasi berkas pengangkut pada primordial cabang, sehingga memfasilitasi transport air dan nutrisi dari batang ke primordium dan memacu pembentukan cabang lateral. Selanjutnya primordium cabang yang baru terbentuk ini karena merupakan jaringan meristem, maka kemudian akan mensintesis auksin sendiri untuk pertumbuhannya menjadi cabang atau untuk pertumbuhan cabang itu sendiri.

Meskipun perlakuan girdling selain menghambat transport auksin juga menghambat transport fotosintat dari daun yang ada di atas girdl sebagai "source" ke bawah girdl, tetapi terjadi pembentukan dan pertumbuhan cabang lateral. Kondisi ini disebabkan karena pada perlakuan girdling ini ketersediaan hara tercukupi dengan dilakukannya pemupukan. Hal ini sesuai dengan pendapat Wareing dan Phillips (1981), yang menyatakan bahwa terhambatnya pertumbuhan cabang lateral menurut "Nutrtive Diversion Theory "disebabkan nutrisi lebih banyak ditransport ke apical batang dibanding ke tunas lateral hanya berlaku pada kondisi defisiensi hara, sedang pada kondisi hara tercukupi kekurangan nutrisi pada nodus tidak menghambat pembentukan cabang lateral.

\section{KESIMPULAN}

Berdasarkan hasil penelitian ini dapat disimpulkan bahwa perlakuan girdling berpengaruh mematahkan dominansi apical batang dan memacu pembentukan tunas lateral pada tanaman Jarak Pagar (Jatropa curcas)

\section{DAFTAR PUSTAKA}

Davies, J. P., (1995), Plant Hoemones : Their Nature, Occurrence and Function. Dalam P.J. Davies (edt) : Plant Hormones : Physiology, Biochemestry and Molecullar Biology, Kluwer Academic Publisher, Boston

Heddy, S., (1989), Hormon Tumbuhan Penerbit CV. Rajawali, Jakarta.

Hoad, G. V (1995), Transport of Hormones in floem of Higher Plant, Plant Growth regulation, 16: 173-337.

Hoad, G. V (1995), Transport of Hormones in floem of Higher Plant, Plant Growth regulation, 16: 173-337.

Hopkis, W.G., (1995), Introduction to Plant Physiology, John Willey and Sons Inc, Singapore.

Lyndon, R.F., (1990), Plant Development The Celluler Basis, London.

Mahmud Z. (2006), Penelitian dan Pengembangan Tanaman Jarak Pagar (Jatropa curcas) Sebagai Bahan Pembuatan Enerji-bio di Indonesia Perlu Mengikuti Peta Jalan Yang Rasional, http//www.perkebunan.litbang.deptan.go.i $\mathrm{d} /$ idex.php?option $=$ com_content $\&$ task $=$ blo gsection\&id=2Itemid $=3$

Prihandana, R dan Hendroko, R. (2006), Petunjuk Budidaya Jarak Pagar, AgroMedia Pustaka, Jakarta.

Taiz L. and E. Zieger, (1998), Plant Physiology, Sinauer Associates, Inc., Publisher, Sunderland, Massachusetts.

Sato, S.S and H. Mori, (2001), Control Outgrowth and Dormancy In Axilary Bud. http://www.plantphysiol.org. 
Salisbury, B and C.W.Ross, (1992), Plant Physiology, Wadsworth Publishing Company, Belmont, California.

Wareing, P.F. and I.D.J. Phillips, (1986), Growth and Differentiation in Plant, The Pergamon Press, Toronto.
Wilkins, M.B, (1989), Fisiologi Tanaman, Bina Aksara, Jakarta. 